\title{
DIAGNÓSTICO DOS EGRESSOS DO CURSO DE ENGENHARIA DE AQUICULTURA DA UNIVERSIDADE FEDERAL DE SANTA CATARINA
}

\author{
Cibeli da Silva \\ Universidade Federal de Santa Catarina \\ cibelidasilva@hotmail.com \\ Jussara Orige Bach Gonçalves \\ Universidade Federal de Santa Catarina \\ jussara.bach@ufsc.br
}

\author{
Gilberto de Oliveira Moritz \\ Universidade Federal de Sanca Catarina \\ gilberto.moritz@ufsc.br \\ Anita Rademaker Valença \\ Universidade Federal de Santa Catarina \\ anita.valenca@ufsc.br \\ Katt Regina Lapa \\ Universidade Federal de Sanca Catarina \\ katt.lapa@ufsc.br
}

Resumo

O estudo teve como objetivo a busca de informações sobre o perfil dos egressos do curso de Engenharia de Aquicultura da UFSC, criado em 1999/1. Devido ao grande número de formados, a técnica utilizada para a coleta de dados foi a aplicação de um questionário online, com 20 perguntas. O link do questionário foi enviado através das redes sociais e alguns por telefone. Dos 460 egressos do curso, 304 responderam ao questionário. Destes, 90,46\% estão empregados, 9,21\% desempregados e $0,33 \%$ aposentados. O objetivo do trabalho foi atingido uma vez que $66 \%$ dos alunos responderam ao questionário, sendo possível realizar um diagnóstico e visualizar de maneira clara onde os profissionais formados estão trabalhando. Por ser um curso novo, tanto na instituição de ensino como no Brasil, foi gratificante constatar que mais de $43 \%$ dos egressos do curso estão atuando no setor aquícola do estado e do país.

Palavras-chave: Egressos. Aquicultura. Atuação Profissional.

\section{DIAGNOSIS OF UNDERGRADUATES OF AQUACULTURE ENGINEERING COURSE AT THE FEDERAL UNIVERSITY OF SANTA CATARINA}

\begin{abstract}
The study aimed to search for information on the profile of graduates of the course of Aquaculture Engineering at UFSC, established in 1999/1. Due to the large number of graduates, the technique used for data collection was the application of an online questionnaire with 20 questions. The questionnaire link was sent through social networks and some over the phone. Of the 460 graduates of the course, 304 answered the questionnaire. Of these, $90.46 \%$ are employed, unemployed $9.21 \%$ and $0.33 \%$ retired. The objective was achieved since $66 \%$ of respondents, and you can make a diagnosis and see clearly where trained professionals are working. Being a new course in both the educational institution and in Brazil, it was gratifying to note that over $43 \%$ of the course graduates are working in the aquaculture sector of the state and the country.
\end{abstract}

Keywords: Graduates. Aquaculture. Professional performance.

\section{DIAGNÓSTICO DE LOS EGRESOS DEL CURSO DE INGENIERÍA DE ACUICULTURA DE LA UNIVERSIDAD FEDERAL DE SANTA CATARINA}

\section{Resumen}

El estudio tuvo como objetivo la búsqueda de información sobre el perfil de los graduados del curso de Ingeniería de Acuicultura de la UFSC, establecida en 1999/1. Debido al gran número de graduados, la técnica utilizada para la recolección de datos fue la aplicación de un cuestionario en línea con 20 preguntas. El enlace de la encuesta fue enviada por los socios y algunas redes telefónicas. De los 460 graduados del curso, 304 respondieron el cuestionario. De estos, se emplean $90.46 \%, 9.21 \%$ en paro y $0,33 \%$ se retiró. El objetivo se ha cumplido ya el $66 \%$ de los encuestados, y se puede hacer un diagnóstico y ver claramente donde están trabajando los profesionales capacitados. $\mathrm{Al}$ ser un nuevo curso, tanto en la institución educativa y en Brasil, fue gratificante observar que más del 43\% de los graduados del curso están trabajando en el sector de la acuicultura del estado y del país.

Palavras clave: Graduados. Acuicultura. Desempeño profesional. 


\section{INTRODUÇÃO}

A Organização das Nações Unidas para Agricultura e Alimentação (FAO) define textualmente aquicultura como "O cultivo de organismos aquáticos, incluindo peixes, moluscos, crustáceos e plantas aquáticas" (FAO, apud UFSC, 2010, p. 08).

Segundo TOMASSO e BRUNE apud UFSC (2010), a aquicultura vem a ser o resultado da união das ciências biológicas com a engenharia. As ciências biológicas participam da nutrição, sanidade animal, fisiologia ambiental, genética, biologia reprodutiva, ecologia aquática e controle de qualidade. Já as engenharias teriam participação através dos sistemas de construção, tecnologia de abastecimento de água, sistemas de aeração, filtragem de água, dinâmica da qualidade de água e desenho de equipamentos.

Nos últimos anos, a aquicultura vem se desenvolvendo muito rapidamente, em resposta à crescente demanda por pescado e derivados, atingindo um nível de desenvolvimento muito além do que se poderia imaginar tempos atrás, quando a piscicultura começou a desenvolver-se. A importância da aquicultura também se deve ao fato de que ela é ainda uma atividade de produção crescente, quando se sabe que a exploração de populações selvagens, em geral, já atingiu o seu máximo potencial (NOMURA, 2010).

O profissional que pretende se formar nesta área, não se enquadra dentro do conceito de engenharia clássica, mas no das ciências agrárias. A engenharia de aquicultura deve ser entendida como uma tecnologia de cunho científico que é aplicada sobre um recurso biológico, como nas ciências agrárias, em contraste com a engenharia clássica (áreas Civil, Mecânica, Elétrica, entre outras) que se aplica sobre recursos não-biológicos. O ensino de aquicultura, até antes da criação do curso de Engenharia de Aquicultura, vinha sendo determinado por cursos afins, principalmente o de Engenharia de Pesca e Agronomia. Alguns cursos como, Engenharia de Pesca, Oceanografia, Zootecnia e Agronomia, oferecem esta disciplina, sendo ela obrigatória ou optativa dependendo do curso e da universidade (UFSC, 2010).

A Universidade Federal de Santa Catarina (UFSC), apresenta uma localização privilegiada, pelas características de natureza geográfica e econômica. A cidade é cercada por águas e permite experiências a um custo relativamente baixo, quando comparado com outras regiões do Brasil (UFSC, 2010).

A criação do Centro de Ciências Agrárias da UFSC previu a instalação do Departamento de Aquicultura, efetivada em 1985, que se constituiu na primeira experiência deste tipo na universidade brasileira. Em nível de graduação o departamento oferece disciplinas para os cursos 
de Agronomia, Biologia, Zootecnia e Engenharia Sanitária da UFSC. Em 1988, foi implantado o curso de Pós-Graduação em Aquicultura em nível de mestrado, sendo reconhecido pelo Ministério da Educação (MEC) em 1997. A graduação em Engenharia de Aquicultura teve início no primeiro semestre de 1999, sendo reconhecida pelo MEC em 2003. Mais tarde, a partir de 2005, o Departamento de Aquicultura implantou o curso de doutorado em aquicultura (UFSC, 2010).

Entre as universidades federais que oferecem o curso temos, além da UFSC: Universidade Federal do Paraná (UFPR), com o curso de Tecnologia em Aquicultura na unidade Palotina e Pontal; Universidade Federal de Minas Gerais (UFMG), com o curso de Aquicultura; Universidade Federal da Fronteira Sul, com o curso de Engenharia de Aquicultura; Fundação Universidade Federal de Rondônia (UNIR), com o curso de Engenharia de Pesca e Aquicultura no campus de Cacoal; e Universidade Federal do Rio Grande do Norte (UFRN), com o curso de Aquicultura e Engenharia de Aquicultura.

Em áreas afins, a Universidade Federal do Amazonas (UFAM), oferece o curso de graduação em Engenharia de Pesca no campus de Manaus; a Universidade Federal de São Paulo (UNIFESP) o curso de Ciências do Mar; Universidade Federal do Piauí (UFPI) o curso de Engenharia de Pesca no campus Ministro Reis Veloso; a Universidade Federal do Ceará (UFC) o curso de Engenharia de Pesca no campus do Piauí; e a Universidade Federal de Sergipe (UFS) o curso de Engenharia de Pesca na sede São Cristovão. Por fim, o Instituto Federal oferece o curso Técnico em Aquicultura em diversos estados do país, entre eles, Santa Catarina, Ceará, São Paulo, Acre, Tocantins, Rio de Janeiro, Paraná e Pernambuco.

O Engenheiro de Aquicultura deverá ser um profissional altamente qualificado que se faça valer das ferramentas conceituais metodológicas e teóricas, as quais teve acesso durante o curso, sendo capaz de contribuir para a produção eficiente de alimentos e derivados de origem aquática a serviços de organizações tanto públicas quanto privadas (UFSC, 2010).

Este estudo foi motivado pelo fato do curso de Engenharia de Aquicultura ser o primeiro do país, já existir há mais de 10 anos, ter mais de 460 alunos formados e pela carência de informações que retratem o perfil do egresso. Desta forma, o estudo se justifica em razão da necessidade de se buscar conhecimento sobre o perfil dos egressos do curso de Engenharia de Aquicultura da UFSC.

Nesse sentido, o presente projeto buscou verificar o destino profissional dos egressos em Engenharia de Aquicultura da Universidade Federal de Santa Catarina, no período de 2003/1 a $2013 / 2$. 


\section{MATERIAIS E MÉTODOS}

Este diagnóstico foi um estudo exploratório o qual utilizou métodos de pesquisa bibliográfica, documental e de campo.

A pesquisa bibliográfica serviu como base para análise dos resultados obtidos através do questionário aplicado aos formados.

A pesquisa documental serviu para levantar dados dos alunos entrevistados, tais como: nome, endereço e telefone. Estes dados foram obtidos com a Chefia do Serviço de Expediente do Curso de Graduação em Engenharia de Aquicultura, através do Sistema de Controle Acadêmico da Graduação (CAGR), além de outros documentos como o Projeto Pedagógico do Curso (PPC).

A pesquisa de campo serviu para investigar e coletar os dados necessários para identificar a real situação do egresso. Devido ao grande número de formados (460) a técnica utilizada para a coleta dos dados foi a aplicação de um questionário online. O questionário foi elaborado com o uso do aplicativo do Google Drive, que serviu para armazenamento e sincronização de arquivos do Google, contendo 20 perguntas, sendo estas objetivas e de múltipla escolha, conforme apresentado no anexo A. Vale ressaltar que, para grande parte dos egressos que responderam ao questionário, foi necessário enviar o link do questionário diversas vezes, através das redes sociais (como Facebook e Whatsapp), e-mail e alguns por telefone.

As perguntas utilizadas no questionário foram as seguintes: nome completo; sexo; semestre que ingressou no curso; tempo de graduação no curso; Índice de Aproveitamento Acumulado (IAA); formação complementar; área temática; situação da formação (em andamento ou concluída); atua na área; empregado atualmente; nome da empresa onde trabalha; estado de atuação; vínculo com a empresa; setor; área; remuneração; registro no CREA; registro ativo; assina ART; informação que julga necessária. Os dados dos formados que responderam ao questionário foram enviados automaticamente para uma planilha no Google Drive, facilitando a análise dos resultados.

O trabalho foi realizado em três etapas. Primeiramente traçou-se um breve histórico da Aquicultura e do Curso de Engenharia de Aquicultura da Universidade Federal de Santa Catarina, juntamente com o PPC. Em seguida, buscou-se retratar a situação atual e profissional dos egressos, os formados do curso de 2003/1 até 2013/2. Por último, foram reunidas todas as informações obtidas, e refletiu-se sobre os resultados obtidos 


\section{RESULTADOS E ANÁLISES}

De 1999/1 a 2013/2 o Curso de Engenharia de Aquicultura da Universidade Federal de Santa Catarina formou 460 alunos. Dos 460 egressos, $\approx 66 \%$ (304) responderam ao questionário aplicado do dia 09/04/2014 à 06/06/2014. Destes, $\approx 65 \%$ (198) são homens e $\approx 35 \%$ (106) mulheres.

Em relação à formação, $\approx 65 \%$ (199) dos egressos informaram que possuíam formação complementar em andamento (82) ou concluída (117). Para os egressos com formação complementar em andamento, 12 estavam realizando a $2^{\mathrm{a}}$ graduação, 11 a especialização, 38 egressos estavam cursando o mestrado e 21 o doutorado, representando $\approx 15 \%$ e $\approx 13 \%, \approx 46 \%$ e $\approx 26 \%$, respectivamente. Entre os egressos com formação complementar concluída, tinham: 4 com a $2^{\mathrm{a}}$ graduação, $38 \mathrm{com}$ a especialização, 67 com mestrado e 8 com doutorado, representando $\approx 3 \%, \approx 33 \%, \approx 57 \%$ e $\approx 7 \%$, respectivamente.

Dos formados em Engenharia de Aquicultura, $\approx 43 \%$ (130) egressos estavam atuando na área aquícola e $\approx 57 \%$ (174) estavam atuando em outras áreas, como apresentado na Figura 1.

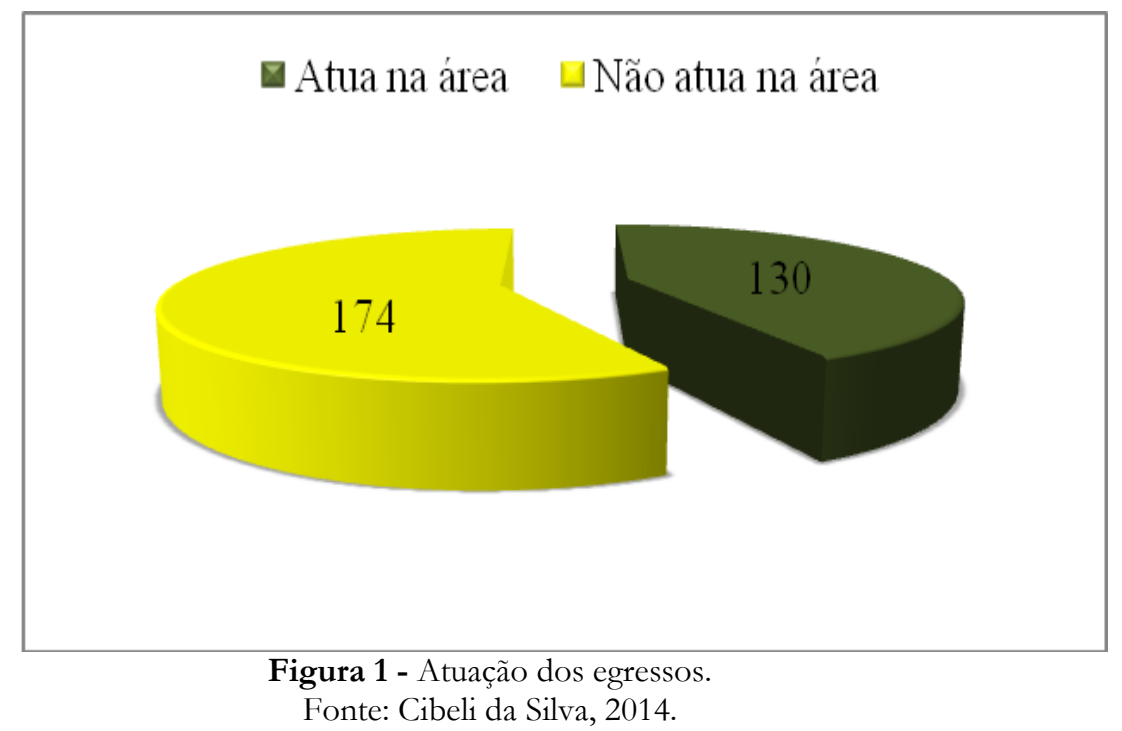

De modo geral, dos 304 egressos que responderam ao questionário, aproximadamente 90,4\%, estavam empregados (275 egressos), 9,21\% estavam desempregados (28 egressos) e 0,33\% estava aposentado (1 egresso), conforme apresentado na Figura 2. 


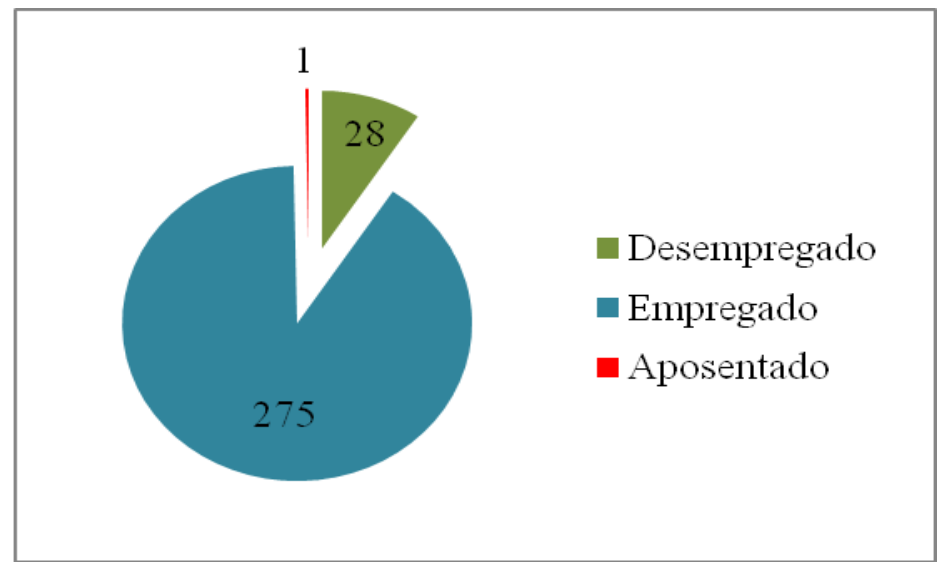

Figura 2 - Situação dos egressos.

Fonte: Cibeli da Silva, 2014.

Considerando as respostas dos egressos que atuam na área aquícola, correspondente a 130 formados, 95\% (124 egressos) estava empregado, contra 5\% (6 egressos) que havia se declarado desempregado.

Da mesma forma, fazendo a análise das respostas dos 174 egressos que informaram que não estavam atuando na área, 151 estavam trabalhando, 22 estavam desempregados e 1 estava aposentado. Observa-se que $\approx 87 \%$ dos egressos se declararam empregados, mesmo informando que não atuam na área aquícola.

Dos locais de atuação dos egressos que estavam atuando na Aquicultura, 3 atuavam na Costa Rica, 1 no Japão e 1 na Inglaterra. Já no Brasil, 2 atuavam em território nacional, 75 no estado de Santa Catarina, 11 no Distrito Federal, 7 no Rio de Janeiro e 6 no estado de São Paulo, entre outros (Figura 3).

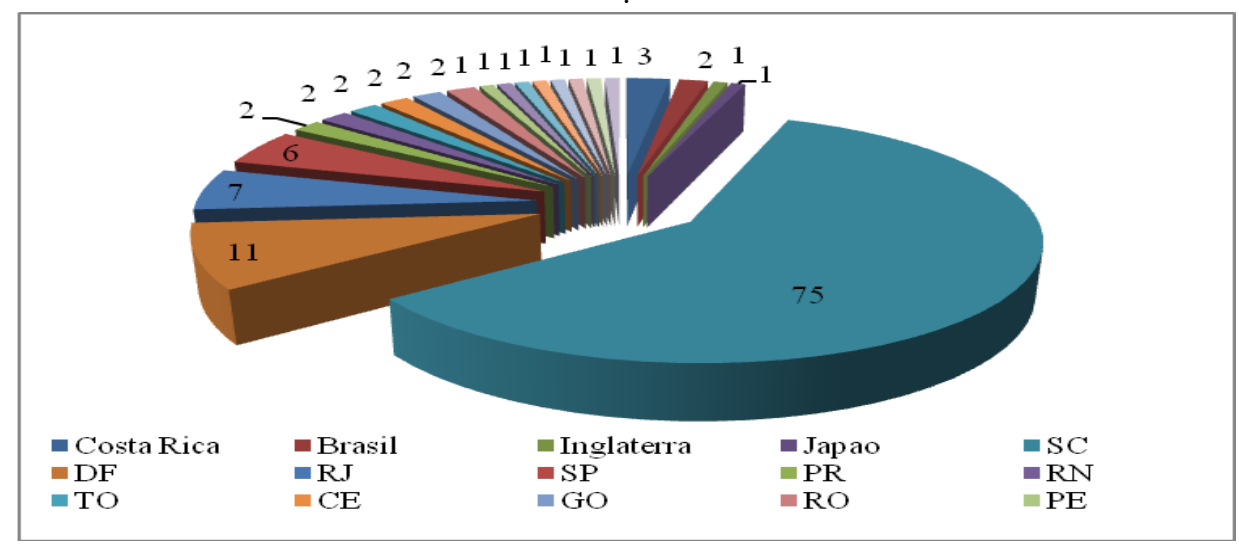

Figura 3 - Local de atuação dos egressos que atuam na Aquicultura Fonte: Cibeli da Silva, 2014.

Entre as empresas, instituições e órgãos que os egressos atuaram, temos: Aquos, UFSC, Cavalo Marinho Criação e Beneficiamento de Frutos do Mar Ltda., Leardini Pescados, 
Piscicultura Piracema, Nicoluzzi, NutriNorte Nutrição Animal, EPAGRI, Ministério da Pesca e Aquicultura, Blue Water Aquaculture, entre outros.

O vínculo dos egressos que atuaram na Aquicultura com empresa pode ser observado na figura abaixo (

). Destes, 6 se declararam desempregados, 11 como empregadores, 17 como autônomos, 41 como bolsistas e 55 como funcionários. Vale ressaltar que a maioria dos egressos trabalhou na condição de funcionário. Apenas 8,5\% dos egressos atuaram na condição de empreendedor do setor aquícola.

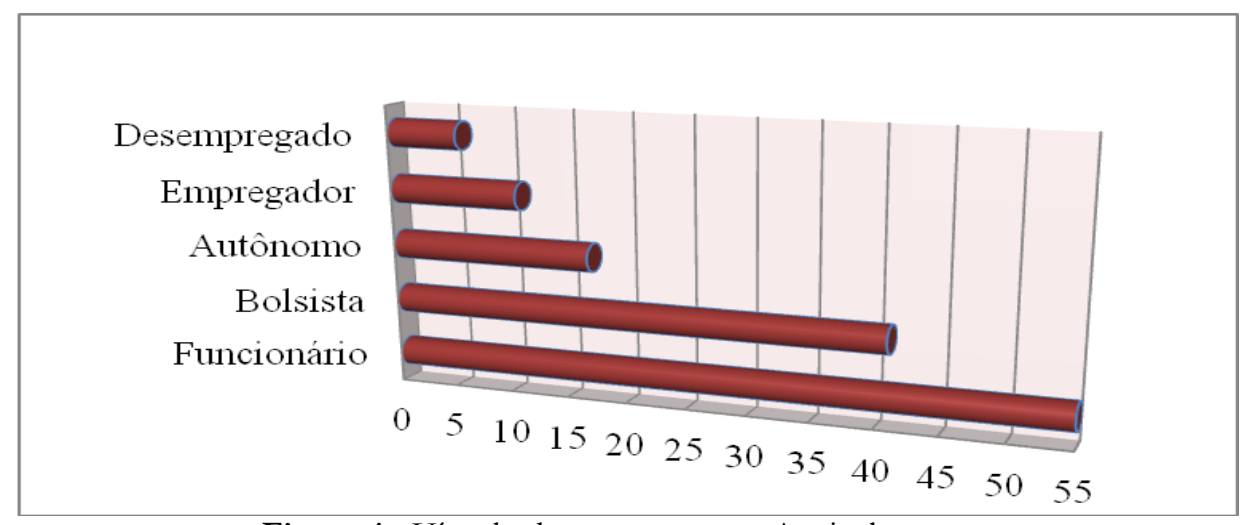

Figura 4 - Vínculo dos que atuam na Aquicultura com a empresa Fonte: Cibeli da Silva, 2014.

Entre o setor de atuação dos egressos contratados como funcionários é possível observar que o setor público apresenta um maior número de egressos em relação ao setor privado, embora essa diferença seja pequena, com 29 atuando no setor público e 26 no setor privado.

Com relação às áreas de atuação destes funcionários (Figura 5), pode-se observar que: tanto no setor público como no privado há maior número de egressos atuando no agronegócio. Já na área de comércio, apenas 1 egresso atuando no setor privado. $\mathrm{Na}$ área de serviços, para o setor público, 14 egressos e no setor privado 6. E por fim, na área industrial, apenas 1 egresso atuando no setor público e 6 no setor privado.

As Figuras 6 e 7 apresentam a remuneração dos funcionários do setor privado e público por área de atuação. Os maiores salários são no setor privado, na área de agronegócio, serviços e comércio, com remunerações acima de 8 salários mínimos. No setor público, as maiores remunerações podem ser observadas na área de agronegócio e serviços, com remunerações acima de 8 salários mínimos Conforme o Decreto $\mathrm{N}^{\circ}$ 8.166, de vinte e três de dezembro de dois mil e treze, o salário mínimo era de R $\$ 724,00$ mensais (BRASIL, 2013). 


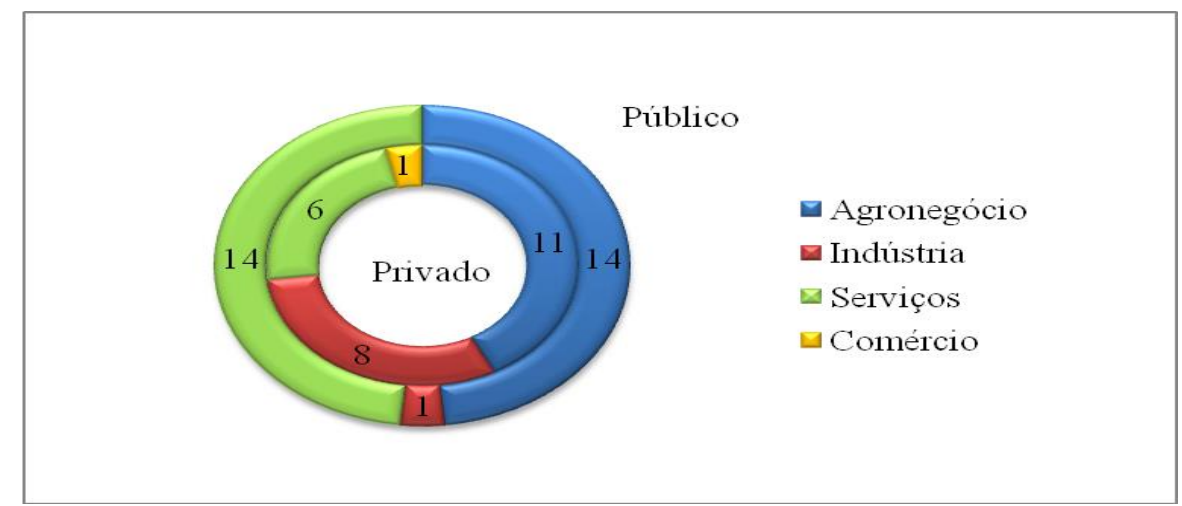

Figura 5 - Área de atuação dos funcionários na Aquicultura - setor público e privado. Fonte: Cibeli da Silva, 2014.

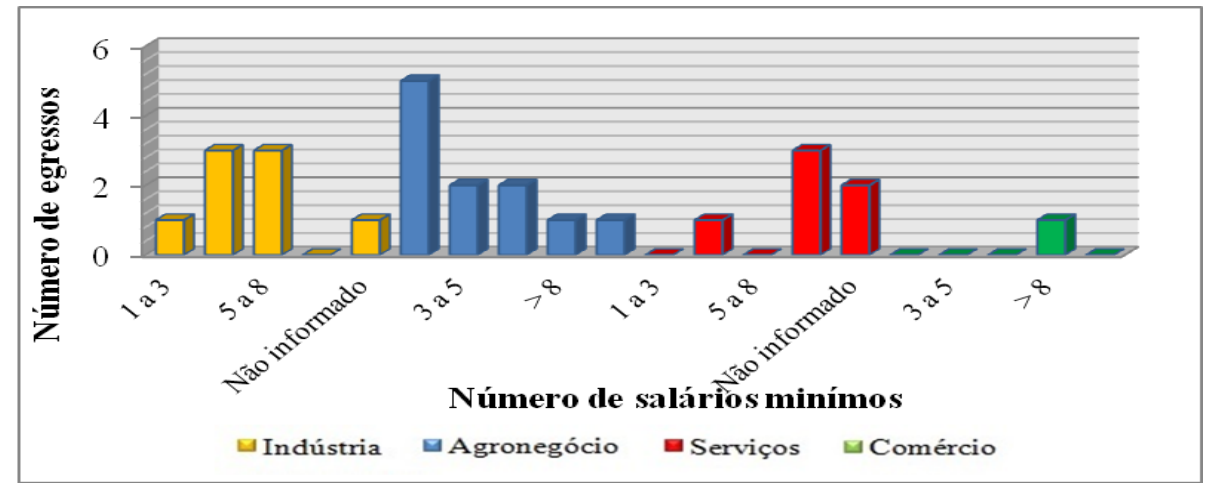

Figura 6 - Remuneração dos funcionários que atuam na Aquicultura - setor privado Fonte: Cibeli da Silva, 2014.

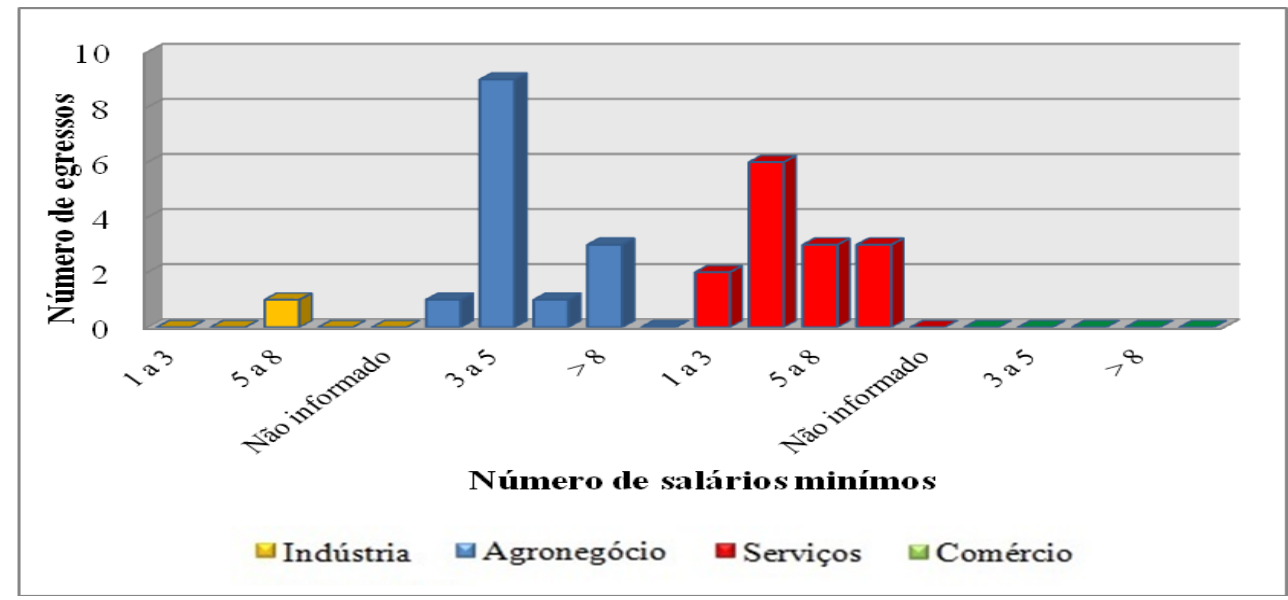

Figura 7 - Remuneração dos funcionários que atuam na Aquicultura - setor público. Fonte: Cibeli da Silva, 2014. 
Entre o setor de atuação dos bolsistas é possível observar que o público representa mais de 75\%, com 37 bolsistas, e o privado apenas 4. Com relação à área de atuação, no setor privado 2 bolsistas atuaram na área de agronegócio, 1 em serviços e 1 em indústria. No setor público, 20 atuaram em agronegócio, 14 em serviços e 3 em indústria. Em relação à remuneração dos bolsistas, foi observado que, no setor privado, destaca-se o agronegócio, com valores de 3 a 5 salários mínimos e 5 a 8 salários. Para o setor público, grande parte dos bolsistas que atuaram na área de agronegócio, as remunerações variam de 1 a 3, 3 a 5 e >8 salários mínimos. $\mathrm{Na}$ área de serviços, a remuneração varia de 1 a 3 a 5 a 8 salários mínimos.

Dos autônomos que atuaram na Aquicultura, 13 eram do setor privado e 4 do setor público. No setor público, 3 atuaram em agronegócio e $1 \mathrm{em}$ serviços. No setor privado, 7 atuaram em agronegócio e 6 em serviços. De acordo com as respostas, não havia autônomos atuando na área de comércio e indústria.

Dos 11 empregadores que atuavam na Aquicultura, todos eram do setor privado. Entre as áreas de atuação destes empregadores (Figura 8), observa-se: 5 em serviços, 5 em agronegócios e 1 em indústria.

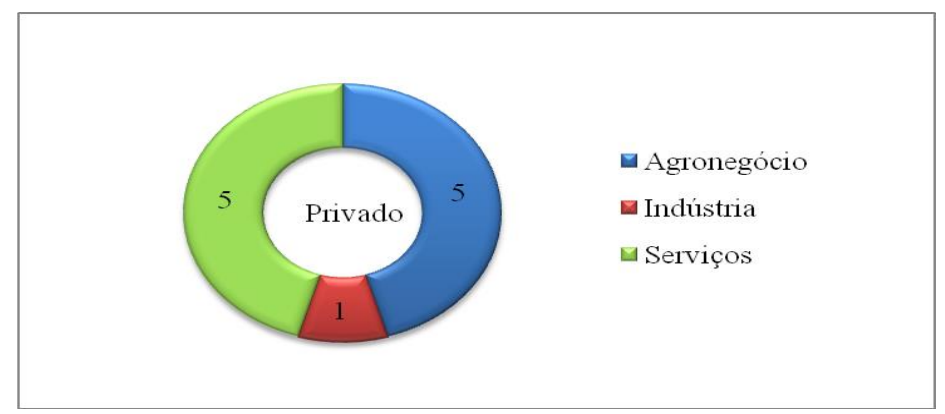

Figura 8 - Área de atuação dos empregadores que atuaram na Aquicultura - setor privado Fonte: Cibeli da Silva, 2014.

Para os empregadores, 4 da área de agronegócios apresentaram uma remuneração superior a 8 salários mínimos e 1 entre 5 a 8 salários mínimos, seguido da área de serviços, com remunerações que variam de 1 a 3 até acima de 8 salários mínimos (Figura 9). Na área de indústria, apenas um com remuneração de 5 a 8 salários mínimos. 


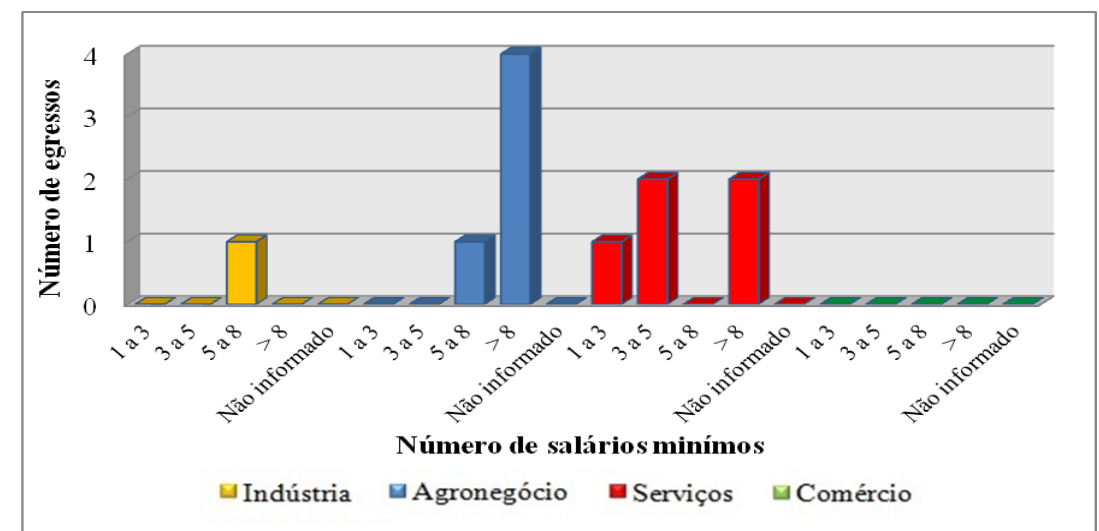

Figura 9 - Remuneração dos empregadores que atuam na Aquicultura - setor privado. Fonte: Cibeli da Silva, 2014.

O Conselho Regional de Engenharia, Arquitetura e Agronomia (CREA) regula as atividades profissionais dessas áreas, tanto em nível superior quanto em nível técnico. A importância de ser um profissional registrado no CREA é enorme, pois comprova que você frequentou um curso reconhecido pelo sistema CONFEA/CREA e está apto a exercer legalmente sua profissão. O CREA fiscaliza, controla, orienta e aprimora o exercício e as atividades profissionais de Engenharia e Agronomia.

Dos 130 Engenheiros de Aquicultura formados, 51\% (67 egressos) possuem registro no CREA. Destes, 49 possuem o registro ativo e 26 anotam formalmente ART (Figura 0).

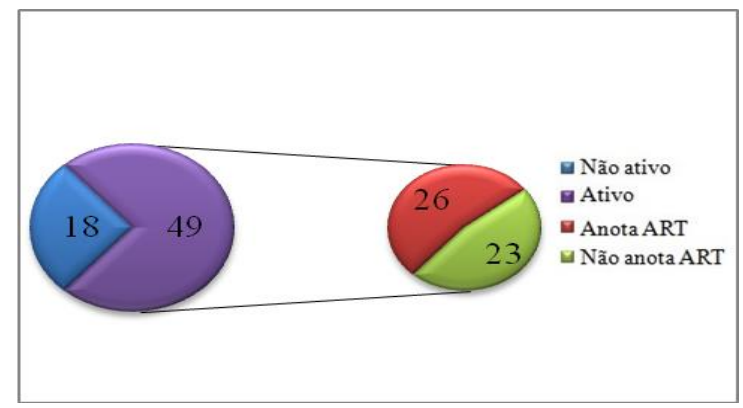

Figura 10 - Situação do registro no CREA dos egressos que atuam na Aquicultura Fonte: Cibeli da Silva, 2014.

Dos locais de atuação dos egressos que não atuavam na Aquicultura, 1 estava na China, 1 na Suíça, 1 na Coréia do Sul e 1 na Irlanda. No Brasil, 111 no estado de Santa Catarina, 18 em São Paulo, 6 no Rio de Janeiro, entre outros (Figura 11).

Foi possível observar que dos 174 formados, 111 permaneceram no estado de Santa Catarina, correspondendo a $64 \%$ do total de egressos que declararam não estar atuando na área. 


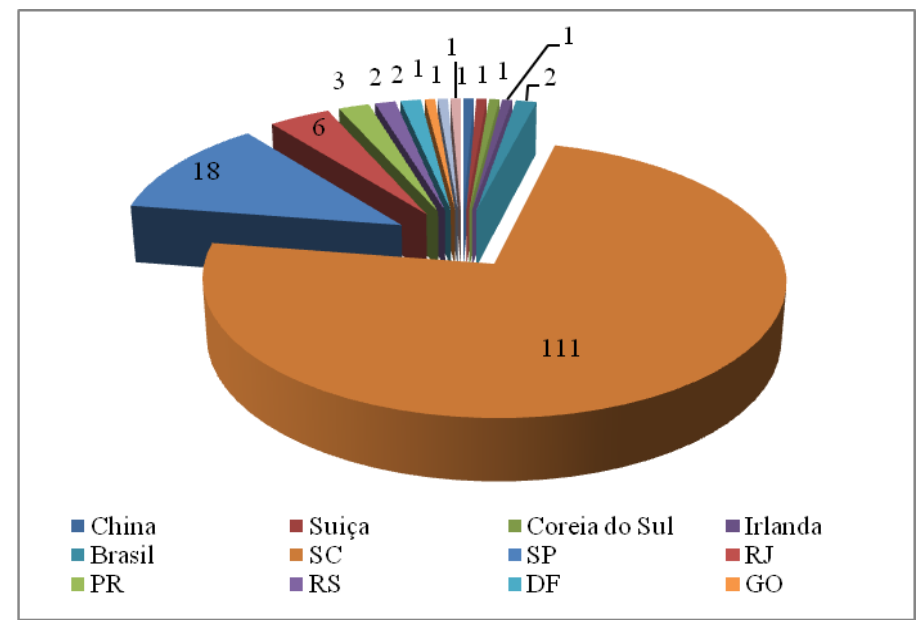

Figura 11 - Local de atuação dos egressos que não atuam na Aquicultura Fonte: Cibeli da Silva, 2014.

Entre as empresas, instituições e órgãos que os egressos, que não atuavam na área de aquicultura, estavam trabalhando, destacam-se: Correios, Governo do Estado de Santa Catarina, Corpo de Bombeiros Militar de Santa Catarina, Secretaria da Fazenda de Santa Catarina, Polícia Militar de Santa Catarina, Petrobrás, Artesano Pizza Bar, entre outros.

O vínculo dos egressos com empresa pode ser observado no gráfico abaixo (Figura 102), sendo 1 aposentado, 22 desempregados, 21 empregadores, 25 autônomos, 14 bolsistas e 91 funcionários.

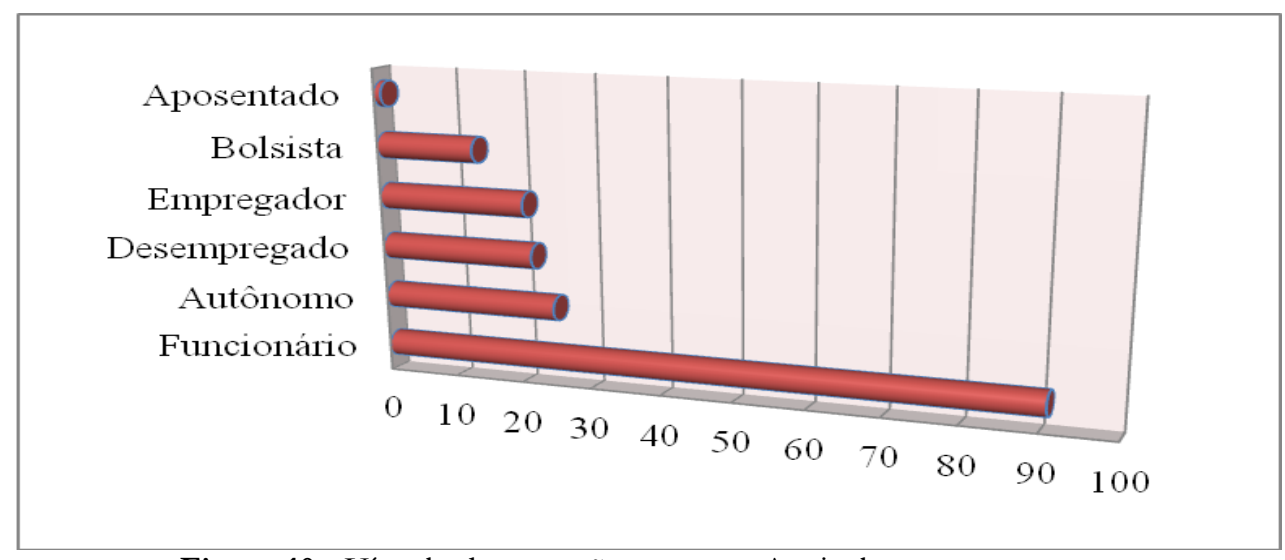

Figura 10 - Vínculo dos que não atuam na Aquicultura com empresa.

Fonte: Cibeli da Silva, 2014.

Apenas um aposentado do setor público atua na área de serviços com uma remuneração superior a 8 salários mínimos.

Pode-se observar que, tanto no setor público como no privado, há maior número de egressos atuando na área de serviços (Figura 11). 


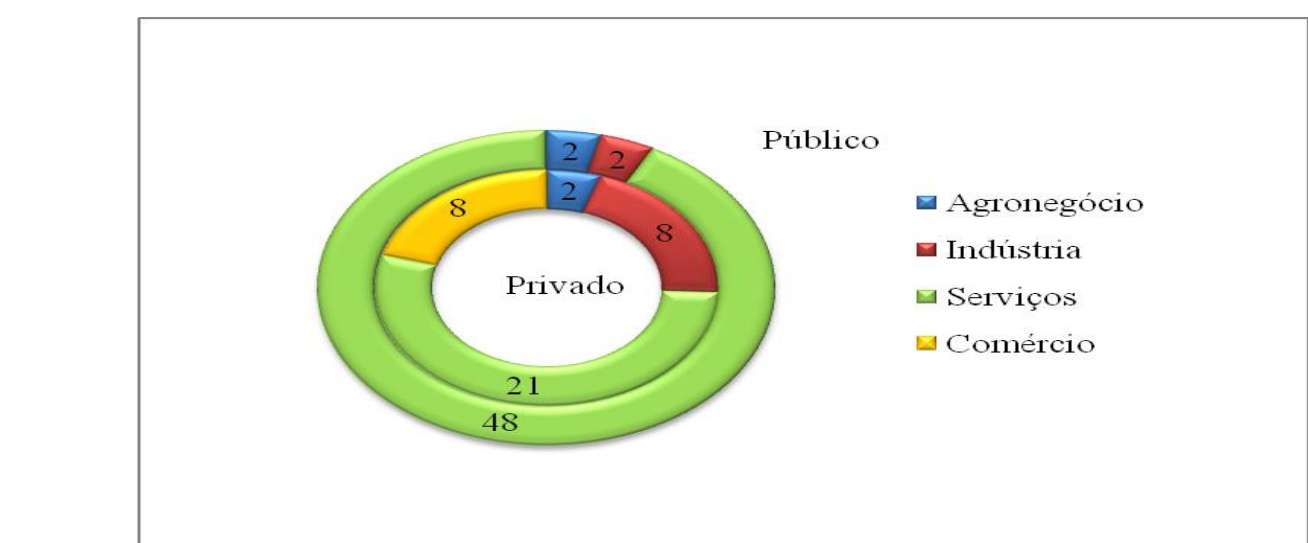

Figura 113 - Área de atuação dos funcionários que não atuam na Aquicultura - setor público e privado. Fonte: Cibeli da Silva, 2014.

A maneira como o diagnóstico foi elaborado, perguntando se o egresso atua ou não atua na área de aquicultura, dificultou a análise de dados, quando comparado com as demais perguntas, como, por exemplo, o nome da empresa que trabalha e o cargo que ocupa. Isto ocorreu, porque não foi considerado, ou analisado, os que atuam em áreas correlatas ou afins a Engenharia de Aquicultura. Além disso, a falta de conhecimento ou a má interpretação do questionário por parte de alguns egressos também pode ter influenciado os resultados do trabalho.

Dos 460 egressos do curso de Engenharia de Aquicultura da UFSC, 304 responderam ao questionário. Destes, $\approx 65 \%$ são homens (198 egressos) e $\approx 35 \%$ mulheres (106 egressos). De modo geral, 90,46\% dos egressos estão empregados (275 egressos), 9,21\% desempregados (28 egressos) e $0,33 \%$ aposentado ( 1 egresso).

Segundo dados do Instituto Brasileiro de Geografia e Estatística - IBGE, em 2013 a taxa de desocupação (indicador que mede a parcela da população desocupada em relação à população em idade de trabalhar) no Brasil, no $4^{\circ}$ trimestre de 2013, foi estimada em 6,2\%. Esta estimativa apresentou redução estatisticamente significativa em relação ao $3^{\circ}$ trimestre de 2013 (6,9\%). No último trimestre de 2013, a Região Nordeste foi a que apresentou a maior taxa, 7,9\%, e a Região Sul, a menor, com 3,8\% (BRASIL, 2013). Entre os egressos do curso de Engenharia de Aquicultura, nota-se que a taxa de desemprego que é de $\approx 9,21 \%$ se manteve um tanto acima da média nacional (6,2\%), comparando com os dados do IBGE.

Entre os que atuam na Aquicultura, nota-se uma resposta inferior a 50\%, com 130 Engenheiros de Aquicultura, o que representa $\approx 43 \%$ do total. Dos que atuam na Aquicultura, 6 estão desempregados, 11 são empregadores, 17 autônomos, 41 bolsistas e 55 funcionários. Entre 
os 174 que não atuam, 1 está aposentado, 22 estão desempregados, 21 são empregadores, 25 autônomos, 14 bolsistas e 91 funcionários.

Por ser um curso novo no mercado nacional, foi gratificante constatar que mais de $43 \%$ dos egressos estão atuando na aquicultura. No entanto, a falta de registros ou referências bibliográficas dificultaram a discussão do trabalho, pois não foram encontrados documentos para analisar e comparar os dados obtidos. Sabe-se por intermédio de entrevista com servidores técnicos da UFSC, que um dos egressos realizou um trabalho semelhante a este, porém seu TCC não está cadastrado e disponível na biblioteca da UFSC.

Segundo dados do Ministério do Trabalho e Emprego (MTE), em 2008, Santa Catarina possuía um total de 524 empresas formais atuando no setor de pesca e aquicultura. Estas empresas, tomando como referência o mês de dezembro de 2008, foram responsáveis por 3.118 empregos com carteira assinada. Segundo o critério adotado para a definição do porte, as micro e pequenas empresas representam, respectivamente, $85,1 \%$ e $12,8 \%$ dos estabelecimentos do setor de pesca e aquicultura do estado. As micro e pequenas empresas juntas geraram 2.176 empregos, o equivalente a $69,8 \%$ dos postos formais de trabalho do setor (SANTA CATARINA, 2010). Em Santa Catarina, temos 75 egressos atuando na aquicultura, sendo que, 8 são empregadores 21 são funcionários, 10 são autônomos e 36 são bolsistas.

Entre os locais de atuação dos egressos que atuam na Aquicultura $\approx 61 \%$ permaneceram no estado de Santa Catarina. De acordo com SANTA CATARINA (2010), a pesca desempenha importante papel na economia catarinense, o estado é o maior produtor de pescado e crustáceos do país. Os cerca de $500 \mathrm{~km}$ de litoral contribuem para que a atividade pesqueira de Santa Catarina seja bastante diversificada, tendo sua produção baseada em diversas espécies de peixes, crustáceos e moluscos, capturados por diferentes tipos de embarcações e métodos de pesca. A aquicultura respondeu por $27 \%$ da produção pesqueira brasileira, representando em 2007 uma produção de 289.049,5 toneladas. A produção aquícola de Santa Catarina, somando a maricultura e a água doce, alcançaram em 2010, o total de 34.795 toneladas, o que equivale a $23,2 \%$ do que produz a pesca extrativa do estado. Em 2007 a maricultura representou $34 \%$ da produção aquícola catarinense. Isso pode justificar o fato de que a maioria dos egressos que atuam na aquicultura permaneceu no estado.

A remuneração dos que atuam na Aquicultura, varia de acordo com o setor, vínculo e área de atuação. Para o setor público, os que atuam na área de agronegócio $(\approx 53 \%)$ e serviços $(\approx$ $41,5 \%$ ) recebem as maiores remunerações, variando de 1 a 3 até $>8$ salários mínimos. No setor privado, as maiores remunerações são na área de agronegócio $(\approx 46,5 \%)$, serviços $(\approx 33 \%)$, e indústria $(\approx 18,5 \%)$. Grande parte dos egressos do setor público que não atuam na Aquicultura, 
atua na área de serviços $(\approx 90 \%)$ e agronegócio $(\approx 6 \%)$. No setor privado, atuam na área de serviços $(\approx 45 \%)$ e comércio $(\approx 40 \%)$. As remunerações variam de 1 a 3 até $>8$ salários mínimos tanto no setor público como no privado. Independente da área de atuação, os cargos públicos concursados possuem remuneração alta, enquanto que, empregos no setor privado dependem do tamanho e da localização da empresa, além do cargo a ser ocupado.

Segundo KRUG (2012), estes profissionais atuam em empresas, associações e cooperativas de produção de organismos aquáticos, em prefeituras, secretarias e empresas públicas, assim como em universidades e centros de pesquisa com interesse voltado para o tema, além de empreenderem em atividades relacionadas com produtos e serviços de origem aquática.

O diploma de graduação dos egressos tem validade para participação em concursos públicos de nível superior, em cursos de especialização e de pós-graduação. Entre os que não atuam na área, aproximadamente 40\% (69 egressos) participaram de concursos públicos e são

funcionários da Polícia Militar, Corpo de Bombeiros, Correios, Ministério da Fazenda, entre outros.

\section{CONSIDERAÇÕES FINAIS}

O objetivo do trabalho foi atingido uma vez que $66 \%$ dos alunos formados em Engenharia de Aquicultura responderam o questionário elaborado em apenas dois meses de pesquisas. Dessa forma, foi possível realizar o diagnóstico e visualizar de maneira clara onde os profissionais formados estão trabalhando.

A divisão do diagnóstico em dois tópicos, entre os que atuam e não atuam na área, alterou o resultado do trabalho, já que impediu considerar aqueles que atuam em áreas correlatas ou afins, aumentando assim o número de egressos que continuam na área da Aquicultura. A não persistência ou desinteresse dos egressos, juntamente com a falta de empreendedorismo fez com que muitos dos egressos desistissem da Aquicultura, migrando para outras áreas.

Por ser um curso novo tanto na instituição de ensino como no Brasil foi gratificante constatar que mais de 43\% dos egressos do curso de Engenharia de Aquicultura da UFSC, está atuando diretamente no setor aquícola do estado e do país. As remunerações variaram de acordo com a área de atuação e setor. Com relação à área de atuação, grande parte dos egressos atua na área de agronegócio e serviços, com destaque para agronegócio. Entre os vínculos com a empresa, grande parte dos egressos são funcionários e bolsistas. O número de empregadores é 
baixo, e isso pode ser fomentado durante o curso, elevando assim o número de egressos empreendedores no setor aquícola.

O presente trabalho abre portas para futuras pesquisas e comparações para avaliar o crescimento e desenvolvimento do curso de Engenharia de Aquicultura e de seus egressos.

\section{REFERÊNCIAS}

BRASIL. DECRETO No 8.166 de 23, de dezembro de 2013, Regulamenta a Lei no 12.382, de 25 de fevereiro de 2011, que dispõe sobre o valor do salário mínimo e a sua política de valorização de longo prazo. Diário Oficial da Republica Federativa do Brasil, Brasília, DF, n. 249, p. 01, 24 de dez. 2013. Seção 1, pt. 1.

BRASIL. Instituto Brasileiro de Geografia e Estatística. Pesquisa Nacional por Amostra de Domicílios Contínua $4^{\text {o }}$ trimestre de 2013. 2013. 35 p.

KRUG, L. C. (org.). VIII Plano Setorial para os Recursos do Mar - PSRM. Formação de Recursos Humanos em Ciências do Mar: Estado da Arte e Plano Nacional de Trabalho 2012-2015 / Organizador Luis Carlos Krug. - Pelotas: Ed: Textos, 2012. 172p.

NOMURA, I. O Futuro da Pesca e da Aquicultura Marinha no mundo. Ciência e Cultura. São Paulo, vol. 62, $\mathrm{n}^{\circ}$ 3. 2010. p. 28-32. Disponível em: http://cienciaecultura.bvs.br/scielo.php ?pid=S0009-67252010000300012\&script=sci_arttext. Acesso em: 16 jun. 2014.

SANTA CATARINA. Serviço Brasileiro de Apoio às Micro e Pequenas Empresas de Santa Catarina. Santa Catarina em Números: pesca e aquicultura. - Florianópolis: Sebrae/SC, 2010. 57p.

SÃO PAULO. CREA/SP. Conselho Regional de Engenharia, Arquitetura e Agronomia de São Paulo. O que é CREA?. 2011. Disponível em: http://www.creasp.org.br/institucional/o-que-eo-crea-sp. Acesso em: 24 jun. 2014.

UFSC - Universidade Federal de Santa Catarina. Curso de Engenharia de Aquicultura. Projeto Político Pedagógico do Curso (PPC) de Engenharia de Aquicultura/CCA/UFSC. Florianópolis: UFSC, 2010. 48 p. 